\title{
RANCANGBANGUN DAN UJI PERFORMANSI SINGLE STIRRING REACTOR (SSR) PUTARAN SEARAH PADA BERBAGAI RPM UNTUK PRODUKSI BIODIESEL
}

\section{DESIGN AND PERFORMANCE TEST OF SINGLE STIRRING REACTOR (SSR) WITH ONE DIRECTION IN VARIOUS ROTATIONS FOR BIODIESEL PRODUCTION}

\author{
Furqon $^{1}$, Abdul Mukhlis Ritonga ${ }^{1}$, Ali Maksum ${ }^{2}$ \\ ${ }^{1}$ Program Studi Teknik Pertanian, Fakultas Pertanian, Universitas Jenderal Soedirman. \\ ${ }^{2}$ Program Studi Ilmu dan Teknologi Pangan, Fakultas Pertanian, Universitas Jenderal Soedirman. \\ $\bowtie$ Komunikasi Penulis, Email: furqon.8@gmail.com \\ DOI: http://dx.doi.org/10.23960/jtep-l.v7i1.9-14
}

Naskah ini diterima pada 22 Maret 2018; revisi pada 21 April 2018; disetujui untuk dipublikasikan pada 27 April 2018

\begin{abstract}
Production of biodiesel by catalytic method requires a stirring system so that triglyceride and methanol having immiscible properties can be well mixed However, applications of biodiesel production still use several reactors and with high rpm. Therefore, it would be better if the biodiesel production process is conducted by using single reactor as for the reaction take place and using low rpm to be more efficient in energy use.The aims of research are to design a single stirring reactor (SSR) and to test its performance with one direction. The design of SSR was done by performing the design stage and calculation of technical analysis. The SSR was made in a batch type and laboratory scale. The concentration of methyl ester was analysis by GC-MS (Gas Chromatography-Mass Spectrometry). The SSR is a reactor tube using Stainless steel 304 with a dimension of $400 \mathrm{~mm}$ height, $150 \mathrm{~mm}$ diameter and thickness of $1 \mathrm{~mm}$. The results showed that SSR was able to work well according to the expected performance, either with or without load. The biodiesel concentration (methyl ester) produced with RBDPO and methanol (1:6), $0.5 \% \mathrm{KOH}$ catalyst, $45^{\circ} \mathrm{C}$ and 30 minutes at $200 \mathrm{rpm}, 350 \mathrm{rpm}$ and $500 \mathrm{rpm}$ respectively was $98.89 \%, 99.55 \%$, and $99.50 \%$, respectively, which means complying the requirements of biodiesel quality based on SNI 7182: 2015.
\end{abstract}

Keywords: Biodiesel; catalyst; design; SSR reactor; performance.

\begin{abstract}
ABSTRAK
Produksi biodiesel dengan metode katalitik membutuhkan sistem pengadukan agar trigliserida dan metanol yang mempunyai sifat tidak saling bercampur dapat bercampur dengan baik. Namun, sebagian besar produksi biodiesel masih menggunakan beberapa reaktor dan menggunakan putaran tinggi. Oleh karena itu, akan lebih baik jika proses produksi biodiesel dilakukan menggunakan satu reaktor sebagai tempat reaksi tersebut dan menggunakan putaran yang tidak terlalu tinggi sehingga lebih efisien dalam penggunaan energi. Tujuan dari penelitian ini adalah merancang single stirring reactor (SSR) dan menguji performansinya dengan putaran searah. Rancangbangun SSR dilakukan dengan melakukan tahapan perancangan dan perhitungan analisis teknik. Alat yang dibuat merupakan tipe batch dan skala laboratorium. Hasil biodiesel (metil ester) dianalisis dengan GC-MS (Gas Chromatography-Mass Spectrometry). Hasil perancangan alat SSR mempunyai dimensi tabung reaktor tinggi $400 \mathrm{~mm}$, diameter $150 \mathrm{~mm}$ dan tebal $1 \mathrm{~mm}$ menggunakan bahan Stainless steel 304. Hasil pengujian mendapatkan bahwa alat mampu bekerja dengan baik sesuai performansi yang diharapkan, baik dengan beban maupun tanpa beban. Hasil uji performansi alat SSR putaran searah saat memproduksi biodiesel dengan bahan RBDPO dan metanol (rasio 1:6), katalis $\mathrm{KOH} 0,5 \%$, suhu $45^{\circ} \mathrm{C}$, dan waktu 30 menit pada putaran $200 \mathrm{rpm}, 350 \mathrm{rpm}$, dan 500 rpm berturut-turut menghasilkan kadar metil ester 98,89\%, 99,55\%, dan 99,50\%, yang berarti sudah memenuhi syarat mutu biodiesel berdasarkan SNI 7182:2015.
\end{abstract}

Kata kunci: biodiesel; katalis; rancangbangun; reaktor SSR; performansi 


\section{PENDAHULUAN}

Konsumsi bahan bakar minyak dan LPG nasional telah melebihi produksi minyak mentah sejak tahun 2001. Khusus solar pada tahun 2013 mencapai gap $-60 \%$ antara produksi kilang Pertamina dan konsumsi secara nasional sampai pada akhirnya pemerintah harus memenuhi kekurangan tersebut dengan jalan impor (Hardadi, 2015). Disamping itu, pemerintah mendukung program pengembangan Bahan Bakar Nabati (BBN), salah satunya biodiesel melalui berbagai kebijakannya. Pemanfaatan biodiesel sebagai bahan bakar alternatif disebabkan oleh karakteristiknya mirip dengan minyak diesel konvensional dan berasal dari sumber yang terbarukan (Kim et al. 2007), tanpa emisi polutan, ketersediaan di alam dapat diperbaharui, sedikit limbah, tidak menyebabkan pemanasan global, harga stabil, dan menciptakan lapangan pekerjaan (Demirbas, 2005; Lee et al, 2007). Konversi minyak nabati kedalam bentuk ester (metil ester) dari asam lemak minyak nabati melalui proses transesterifikasi (Hamid dan Yusuf 2002; Knothe et al. 2005), dan guna mempercepat proses transesterifikasi digunakan katalis. Katalis yang biasa digunakan dalam produksi biodiesel secara katalitik adalah katalis basa. $\mathrm{NaOH}$ dan $\mathrm{KOH}$ adalah jenis basa kuat yang dapat terlarut dalam metanol dan etanol (Marchetti et al 2005). Selain itu, untuk mempercepat terjadinya reaksi juga meningkatkan energi aktivasi dilakukan dengan cara menaikkan suhu dan jumlah energi tumbukan aktif (Panggabean, 2011).

Pengadukan merupakan salah satu metode meningkatkan frekuensi tumbukan sehingga reaksi berjalan lebih cepat. Pengadukan yang kuat (rigorous mixing) dilakukan agar trigliserida dan methanol yang bersifat immiscible (tidak saling tercampur) dapat bercampur dengan baik. Namun, beberapa peneliti menggunakan sistem ini dalam bagianbagian yang terpisah dan pada putaran yang tinggi. Simatupang dkk (2016) menggunakan kecepatan putar 1050, 1100, dan $1200 \mathrm{rpm}$ untuk mengetahui kualitas fisika biodiesel dari minyak kelapa. Hasilnya menunjukkan bahwa putaran terbaik untuk menghasilkan biodiesel dengan kualitas terbaik adalah pada putaran 1100 rpm. Hambali dkk (2007) menyatakan putaran yang baik untuk produksi biodiesel adalah 300-500 rpm dengan suhu $55^{\circ} \mathrm{C}$ dan waktu 30-45 menit. Oleh karena itu, akan lebih baik jika proses produksi biodiesel menggunakan satu komponen mesin sebagai tempat terjadinya reaksi tersebut dan menurunkan putarannya sehingga lebih efisien dalam penggunaan energi. Hal ini dapat dilakukan dengan teknologi single stirring reactor (SSR).

\section{BAHAN DAN METODA}

\subsection{Alat dan Bahan}

Alat yang digunakan dalam penelitian ini adalah Prototipe SSR (Gambar 1), thermostat (REXC100), termokopel tipe K, termometer air raksa, hybrid recorder (Yokogawa), GC-MS (untuk analisis hasil). Peralatan penunjang yang digunakan antara lain: gelas ukur $250 \mathrm{ml}$ (Iwaki pyrex), gelas ukur $500 \mathrm{ml}$ (Iwaki pyrex), gelas ukur $50 \mathrm{ml}$ (Iwaki pyrex), labu reaksi (Iwaki pyrex), Erlenmeyer (Iwaki pyrex), timbangan digital (Adam AQT200), corong pemisah, $\mathrm{pH}$ meter (Hanna), evaporator, botol sampel 120 $\mathrm{ml}$. Bahan yang digunakan dalam penelitian ini meliputi minyak goreng kelapa sawit (Refined Bleached Deodorized Palm Oil-RBDPO), metanol (teknis) dan $\mathrm{KOH}$ (Merck-pellets, for analysis). Serta akuades.

\subsection{Metode Penelitian}

Penelitian dibagi dalam dua tahap, yang pertama merancangbangun SSR dan kedua secara eksperimental memproduksi biodiesel menggunakan katalis homogen ( $\mathrm{KOH})$.

Tahap rancang bangun diawali dengan konsep desain yang disusun berdasarkan properti yang dimiliki bahan atau material yang digunakan sehingga sesuai dengan peruntukannya, kemudian melakukan tahapan perancangan yang meliputi perancangan fungsional, perancangan struktural dan analisis teknik. Perancangan dimulai dari tahapan pemilihan desain dan penentuan physical properties dari setiap bahan yang digunakan guna perhitungan saat analisis teknik. Eksperimental pada sistem produksi yang digunakan dalam penelitian ini adalah sistem batch. Rasio molar minyak dan metanol yang digunakan 1:6 (Reyes et al., 2010),

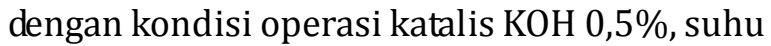
$45^{\circ} \mathrm{C}$, dan waktu 30 menit pada putaran $200 \mathrm{rpm}$, 


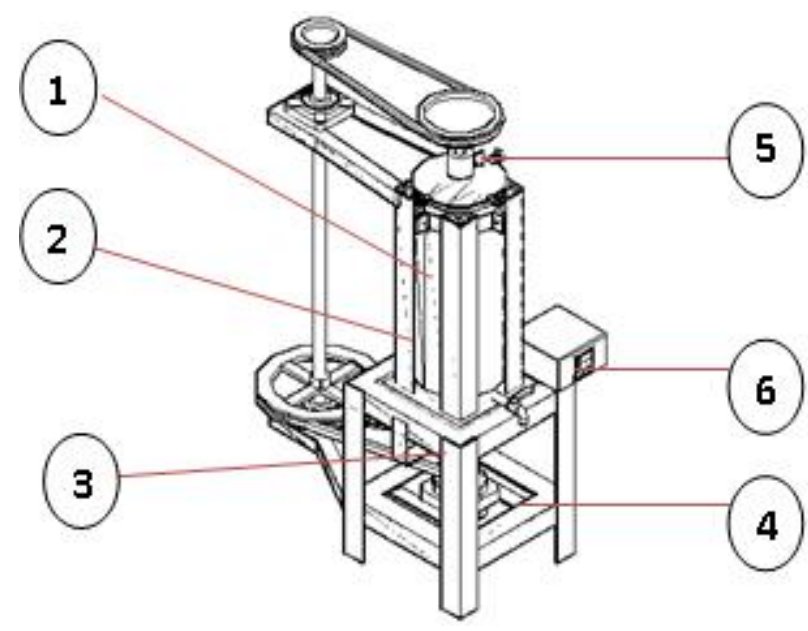

Keterangan

1. Tabung Reaktor

2. Rangka utama

3. Pemanas (heater)

4. Motor listrik

5. Unit pengaduk

6. Thermostat

Gambar 1. Desain prototipe single Stirring Reactor (SSR)

$350 \mathrm{rpm}$, dan $500 \mathrm{rpm}$. Sampel hasil penelitian (biodiesel) dianalisis menggunakan GC-MS untuk mendapatkan kadar metil ester dari setiap percobaan yang dilakukan.

\section{HASIL DAN PEMBAHASAN}

\subsection{Rancangbangun Single Stirring Reactor (SSR)}

Rancangbangun dimulai dengan tahapan desain yang telah terkonfirmasi, menurut Pahl et al (2007) setidaknya ada empat tahapan utama dalam perancangan yaitu perencanaan dan klarifikasi, konsep desain, perwujudan dan desain detail Tahap pemilihan desain dilakukan dengan memperhatikan faktor ergonomis sehingga operator nyaman dalam mengoperasikan alat yang dibuat. Komponen SSR yang telah dibuat terdiri dari:

(1) Tabung Reaktor berfungsi sebagai tempat mencampur (mereaksikan) bahan untuk memproduksi biodiesel. Tabung terbuat dari stainless steel dengan ketebalan $2 \mathrm{~mm}$, diameter $150 \mathrm{~mm}$ dan tinggi $400 \mathrm{~mm}$.

(2) Rangka berfungsi sebagai penopang dan tempat memasang komponen reaktor. Rangka reaktor biodiesel terbagi atas rangka utama dan rangka transmisi. Rangka utama berfungsi untuk menopang motor, heater, dan tabung reaktor, sedangkan rangka transmisi berfungsi untuk menopang keseluruhan sistem transmisi yang ada. Rangka utama terbuat dari besi siku (profil L) ukuran $35 \mathrm{~mm} \times 35 \mathrm{~mm}$ dengan tebal 2 mm yang memiliki ukuran panjang dan lebar yang sama yaitu $260 \mathrm{~mm}$ dan tingginya 710 $\mathrm{mm}$. Rangka transmisi terbuat dari besi siku yang berbentuk $\mathrm{Y}$ dengan ukuran $30 \mathrm{~mm} \mathrm{x}$ $30 \mathrm{~mm}$ dengan tebal $2 \mathrm{~mm}$. Rangka transmisi terbagi menjadi 2 bagian yaitu bawah memilki panjang $245 \mathrm{~mm}$ dan atas yang memiliki panjang $325 \mathrm{~mm}$.

(3) Heater berfungsi sebagai sumber pemanas yang digunakan untuk memanaskan bahan baku yang ada di dalam tabung reaktor. Heater memiliki daya sebesar $350 \mathrm{~W}$.

(4) Tenaga Penggerak (motor listrik). Motor listrik berfungsi sebagai sumber penggerak (putaran) yang merupakan motor listrik AC yang memiliki daya sebesar $120 \mathrm{~W}$, kecepatan sebesar $1400 \mathrm{rpm}$. Motor listrik dipasang di bagian bawah agar lebih ergonomis dan aman dalam mengoperasikan reaktor.

(5) Pengaduk berfungsi untuk mencampur bahan-bahan pembuat biodiesel dalam tabung sehingga bereaksi secara maksimal. Mekanisme kerja pengaduk adalah dengan putaran yang ditransmisikan dari motor. Bahan yang digunakan juga harus anti korosi seperti halnya bahan untuk tabung reaktor karena akan bersentuhan langsung dengan bahan yang direaksikan. Pengaduk ini terbuat dari stainless steel yang terdiri atas batang dan baling-baling (blade). Batang pengaduk memiliki panjang $450 \mathrm{~mm}$ dan diameter poros $10 \mathrm{~mm}$. Blade memiliki panjang jari-jari $60 \mathrm{~mm}$ dan tebal $1 \mathrm{~mm}$ dengan jumlah sudu sebanyak dua. Blade pada pengaduk ini terdapat 2 pasang dimana terletak di ujung dan tengah dengan jarak pisah $160 \mathrm{~mm}$. 
(6). Thermostat merk RKC tipe REX-C100FK02$\mathrm{V}$ berfungsi untuk mengatur suhu operasi sesuai kebutuhan operasi yang dihubungkan dengan termokopel tipe $\mathrm{K}$ dan heater, sehingga suhu operasi pada bahan akan lebih terkontrol dan sesuai dengan kebutuhan yang diinginkan. Suhu yang ditentukan untuk percobaan ini sebesar $45^{\circ} \mathrm{C}$. Hasil percobaan dapat beroperasi baik dengan ketelitian $(+/-$ ) $2^{\circ} \mathrm{C}$ dari setting point.

\subsection{Hasil Pengujian Reaktor Biodiesel SSR}

\subsubsection{Kecepatan putaran}

Kecepatan putaran (rpm) dilakukan pengukuran kembali guna memastikan konsistensi putaran alat. Kecepatan yang dirancang meliputi kecepatanpuli pereduksi dan kecepatan pulipengaduk yang berturut-turut $200 \mathrm{rpm}, 350$ rpm, dan $500 \mathrm{rpm}$.

Tabel 1. Hasil uji kinerja kecepatan

\begin{tabular}{ccc}
\hline No & Unit & Kecepatan (rpm) \\
\hline 1. & Puli pereduksi & 350 \\
2. & Uji Pengaduk 1 & 200 \\
3. & Uji Pengaduk 2 & 350 \\
4. & Uji Pengaduk 3 & 500
\end{tabular}

Sumber: Data pengukuran

Berdasarkan Tabel 1, besarnya kecepatan masih sesuai dengan perancangan sebagaimana pada saat dilakukan uji kinerja tanpa beban. Hal ini menunjukkan bahwa beban yang digunakan tidak berpengaruh terhadap kecepatan (rpm) karena sifat bahan yang tidak berpengaruh terhadap torsi yang terjadi dan desain blade yang tidak menimbulkan gesekan yang besar.

\subsubsection{Kadar metil ester}

Pengadukan merupakan proses penting dalam pembuatan biodiesel karena menyebabkan reaktan bercampur, bertumbukan dan bereaksi. Keberhasilan proses pembuatan biodiesel dipengaruhi oleh putaran pengadukan karena tingkat homogenisasi akan berpengaruh terhadap reaksi transesterifikasi yang terjadi. Menurut (Wahyuni dkk., 2015) bahwa transesterifikasi tidak akan berlangsung baik jika campuran bahan tidak dihomogenisasi.

Berdasarkan hasil penelitian, variasi kecepatan pengadukan berpengaruh terhadap kualitas (kemurnian) biodiesel yang dihasilkan. Gambar 2 menunjukkan bahwa variasi kecepatan pengadukandari kecepatan pengadukan $200 \mathrm{rpm}$ menghasilkan kadar metil ester sebesar 98,89 \%, kecepatan 350 rpm sebesar 99,55 \%dan kecepatan $500 \mathrm{rpm}$ sebesar 99,50\%. Hasil tersebut menunjukkan putaran optimum kecepatan pengadukan untuk menghasilkan biodiesel yang berkualitas dengan menggunakan SSR biodiesel. Sebagaimana yang dijelaskan oleh (Simatupang dkk, 2016) bahwa keadaan ini menunjukkan besarnya kecepatan pengadukan optimum agar menghasilkan biodiesel yang berkualitas dimana dalam penelitian ini menggunakan reaktor biodiesel SSR. Secara umum semua kualitas biodiesel yang dihasilkan sudah memenuhi standar SNI 7182:2015.

Penggunaan putaran pada 200, 350, dan $500 \mathrm{rpm}$ ditujukan untuk menurunkan putaran yang selama ini sudah digunakan supaya lebih hemat energi yang digunakan saat produksi biodiesel selain itu putaran yang kuat/tinggi dapat menyebabkan aliran didalam tangki membentuk

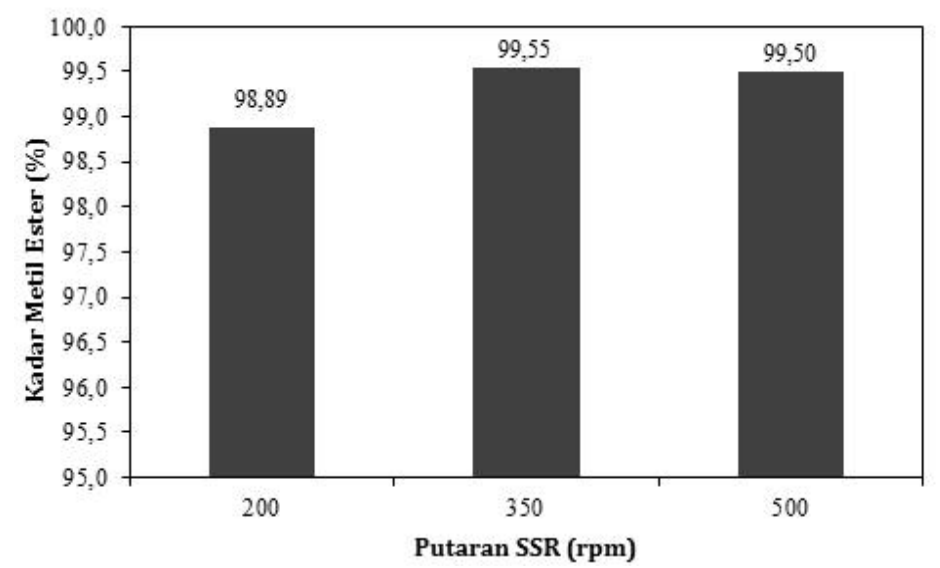

Gambar 2. Grafik hubungan kecepatan pengadukan dan kadar metil ester. 
vortex (McCabe et al, 1993). Simatupang dkk (2016) menggunakan kecepatan putar 1050, 1100, dan 1200 rpm untuk mengetahui kualitas fisika biodiesel dari minyak kelapa, hasilnya putaran terbaik untuk menghasilkan biodiesel dengan kualitas terbaik pada putaran $1100 \mathrm{rpm}$. Hambali dkk (2007) menyatakan putaran yang baik untuk produksi biodiesel adalah 300-500 rpm dengan suhu $55^{\circ} \mathrm{C}$ dan waktu 30-45 menit. Selain berpengaruh terhadap proses transesterifikasi, ternyata kecepatan pengadukan berpengaruh terhadap penggunaan katalis. Sari (2016) menjelaskan bahwa pemakaian katalis dapat diturunkan dengan meningkatkan intensitas tumbukan partikelpartikel melalui proses pengadukan dan pencampuran dalam reaktor. Peningkatan pengadukan menyebabkan molekul-molekul akan lebih sering bertabrakan dengan dambak (benturan) yang lebih besar, sehingga bergerak lebih cepat dan menghasilkan reaksi kimia.

Menurut Luthfiyati dkk (2008), bahwa peningkatan kecepatan pengadukan pada proses transesterifikasi menyebabkan peningkatan konversi biodiesel yang dihasilkan dan karakteristik fisik biodiesel yang cenderung lebih baik (memenuhi standar mutu). Kecepatan pengadukan berpengaruh besar pada tahap awal reaksi. Reaktan-reaktan yang terlibat dalam transesterifikasi merupakan bahan yang tidak saling campur, sehingga pada awal reaksi reaktan-reaktan membentuk dua fasa. Pada kondisi tersebut transfer massa rendah, yang mengakibatkan laju reaksi menjadi lambat. Saat metil ester sudah terbentuk, maka metil ester tersebut dapat bertindak sebagai pelarut reaktan-reaktan tersebut sehingga terbentuk sistem satu fasa dan reaksi menjadi lebih maksimal.

Tahap awal reaksi kecenderungan tumbukan antara ion metoksida molekul trigliserida lebih besar sehingga laju pembentukan metil ester terjadi dengan cepat. Peningkatan suhu akan meningkatkan energi kinetik reaktan-reaktan untuk mengatasi energi aktivasi. Peningkatan kadar metil ester terjadi karena tumbukan antar reaktan semakin sering terjadi dengan semakin lamanya reaksi, sehingga produk yang terbentuk semakin bertambah. Pada saat tertentu jumlah metil ester cenderung tetap karena salah satu reaktan telah habis bereaksi, kemungkinan adalah trigliserida karena metanol disediakan dalam keadaan berlebih. Rendemen metil ester yang tinggi pada pembuatan biodiesel dapat disebabkan karena berasal dari bahan baku dengan karakteristik yang baik, yaitu nilai bilangan asam minyak kelapa sawit yang rendah $(0,32 \%)$.

Dapat disimpulkan bahwa reaktor biodiesel SSR mampu menghasilkan biodiesel dengan kualitas yang baik (SNI 7182:2015) dengan beberapa variasi kecepatan pengadukan yang digunakan dan setiap kecepatan berpengaruh terhadap kualitas biodiesel yang dihasilkan.

\section{KESIMPULAN}

1. Teknologi single stirring reactor (SSR) memiliki dimensi tinggi tabung reaktor 400 $\mathrm{mm}$, diameter $150 \mathrm{~mm}$ dan tebal $1 \mathrm{~mm}$ menggunakan bahan Stainless steel 304, berkapasitas 3,6 L dan dapat beroperasi dengan baik pada percobaan tanpa maupun dengan beban.

2. Hasil uji performansi alat SSR putaran searah saat memproduksi biodiesel dengan bahan minyak kelapa sawit dan metanol (1:6), katalis $\mathrm{KOH} 0,5 \%$, suhu $45^{\circ} \mathrm{C}$, dan waktu 30 menit pada putaran $200 \mathrm{rpm}, 350 \mathrm{rpm}$, dan $500 \mathrm{rpm}$ berturut-turut menghasilkan kadar metil ester 98,89\%, 99,55\%, dan 99,50\%, yang berarti sudah memenuhi syarat mutu biodiesel berdasarkan SNI 7182:2015.

\section{UCAPAN TERIMA KASIH}

Disampaikan ucapan terima kasih kepada Lembaga Penelitian dan Pengabdian kepada Masyarakat Universitas Jenderal Soedirman karena telah membiayai penelitian ini melalui Riset Peningkatan Kompetensi tahun 2017 nomor Kept. 1248/UN23.14/PN.01.00/2017. 


\section{DAFTAR PUSTAKA}

Demirbas, A. 2005. Biodiesel production from vegetable oils via catalytic and noncatalytic supercritical methanol transesterification methods. Progress in Energy and Combustion Science. 31: 466487.

Gerpen, J. V. 2005. Biodiesel Processing and Production. Jurnal Fuel Processing Technology. 86: 1097-1107

Hambali, E., S. Mujdalipah, A.H. Tambunan, A.W. Pattiwiri, and R. Hendroko. 2007. Teknologi Bioenergi. Agromedia Pustaka. Jakarta.

Hamid T.S., R. Yusuf. 2002. Preparasi Karakteristik Biodiesel dari Minyak Kelapa Sawit. Makara Teknologi, 6(2): 6065.

Hardadi, R. 2015. Kondisi Pasokan dan Permintaan BBM di Indonesia dan Upaya Pertamina dalam Pemenuhan Kebutuhan BBM Nasional. Direktorat Pengolahan. PT. Pertamina (Persero).

Kim, J.W., S.T. Hong, J.S. Lim. 2007. Transeseerification of Palm Oil Using Supercritical Methanol. Theories and Application of Chem. Eng. 13: 834 - 837.

Lee, S., J.G. Speight, S.K. Loyalka. 2007. Handbook of Alternative Fuel Technologies. CRC Press. New York.

Luthfiyati, A., Yuswono, dan K. Wijaya. 2008. Kajian Pengaruh Temperatur dan Kecepatan Pengadukan terhadap Konversi dari Minyak Sawit Menggunakan Abu Tandan Kossong Sawit sebagai Katalis. Makalah, dalam Seminar Nasional Kimia XVIII, UGM Yogyakarta.

Marchetti, J.M., V.U. Miguel, A.F. Errazu. 2007. Possible Methods for Biodiesel Production. Renewable and Sustainable Energy Reviews. 11: 1300 - 1311

McCabe W.L., J.L. Smith, P. Harriott. 1993. Unit Operations of Chemical Engineering. McGraw-Hill,Inc. New York, USA.
Pahl G., W. Beitz, J. Feldhusen, K. Grote. 2007. Engineering Design. Springer Publishing. London.

Panggabean, S. 2011. Analisis Kinetika Reaksi Transesterifikasi pada Produksi Biodiesel Secara Katalitik dengan Static Mixing Reactor. Tesis. Bogor: Institut Pertanian Bogor.

Reyes J.F., P.E. Malverde, P.S. Melin, J.P. De Bruijn. 2010. Fuel. 89: 1093 - 3098.

Sari, S. P. 2016. Analisis Pengaruh Penggunaan Static Mixing terhadap Kebutuhan Katalis dalam Produksi Biodiesel. Tesis. Bogor: Institut Pertanian Bogor.

Simatupang, R.A, Ramli, dan Mahrizal. 2016. Optimasi Kecepatan Pengadukan dan Waktu Pengadukan terhadp Kualitas Fisika Biodiesel dari Minyak Kelapa. Jurnal Pillar Of Physics. 7: 89-96

Wahyuni, S, Ramli, dan Mahrizal. 2015. Pengaruh Suhu dan Lama Pengendapan terhadap Kualitas Biodiesel dari Minyak Jelantah. Jurnal Pillar Of Physics. 6: 3340. 